\title{
La edad adolescente de la mujer. Estereotipos y prototipos audiovisuales femeninos adolescentes en la propuesta de Disney Channel
}

\section{Woman Teenage Years. Audiovisual Female Stereotypes and Prototypes in Disney Channel}

\author{
Virginia Guarinos \\ Universidad de Sevilla \\ guarinos@us.es
}

\begin{abstract}
Resumen
A pesar de que la mujer adolescente y preadolescente ocupa buena parte de las imágenes de la publicidad y de los relatos televisivos o cinematográficos, son muy escasos los trabajos de investigación dedicados a la representación de la misma. Las edades de vida de la mujer parecen haber sido silenciadas durante largo tiempo, especialmente la edad madura, la vejez y la adolescencia. Este trabajo pretende acercarse a la construcción que de ella se hace en un medio que hace de la niña-joven "adolescente" una de sus banderas de identificación: Disney Channel, en comparación con productos audiovisuales de otras cadenas.
\end{abstract}

Palabras clave: Mujer, adolescencia, ficción, televisión, género.

\begin{abstract}
Although the teen and preteen woman occupies much of the images in advertising and film and television stories, only a little few research works are devoted to her representation. The ages of women's lives appear to have been silenced for a long time, especially middle age, old age and adolescence. This study attempts to approach the construction of this type of woman done in a media that makes the female teenager an identification flag: Disney Channel, compared to audiovisual products of others TV channels.
\end{abstract}

Key words: Woman, adolescent, fiction, television, gender. 


\section{Introducción}

Los estudios de las mujeres desde el área de conocimiento de la Comunicación Audiovisual han dedicado buena parte de su trabajo al sector cinematográfico. No obstante, además de los medios emergentes, la televisión es un medio de alta influencia en el desarrollo social de las masas. Por otro lado, el perfil femenino al que estos estudios se han venido dedicando parecen haber desoído la máxima de Teresa de Lauretis sobre la diversidad de la mujer y la necesidad de atender los estudios de Teoría Fílmica Feminista no de la mujer sino de las mujeres, buscando sus diferencias sociales, étnicas, religiosas, culturales, económicas... Y, por qué no, de edad. Esta contribución pretende estudiar la construcción de un tipo de mujer marginado en los estudios audiovisuales de género: el de la mujer adolescente. La adolescencia se resume tradicionalmente como etapa de conflictos internos y relacionales para quien pasa por ella. El adolescente es un sujeto que de forma transitoria se ve afectado por la susceptibilidad y la indecisión. El deseo de libertad y de toma de decisiones lo convierten en un ser permeable y, por tanto, susceptible de convertirse en presa fácil de discursos ideológicos o publicitarios. En el caso que se aborda, Disney Channel, lejos de ser un canal para niños, es un canal destinado a adolescentes y, más concretamente, mujeres. La mayor parte de las series y películas programadas en él emite con profusión un perfil prototípico de mujer adolescente que hasta ahora en España estaba muy reducido en emisión a través de canales de pago. Desde la emisión en abierto por TDT este canal es un asiduo de los hogares, invadiendo las mentalidades de las niñas-jóvenes españolas.

Se ha partido de un análisis cuantitativo de la parrilla para entrar en un análisis cualitativo del discurso sobre las producciones emitidas en España a través de Disney Channel en abierto a través de la TDT. Dicho análisis parte de la rejilla de estudio de personajes desde la narrativa audiovisual que toma en cuenta las tres perspectivas de construcción de las esferas de acción: física (rasgos indiciales y artifactuales), psicológica y sociológica; además de la contextualización de los mismos en escenarios, situaciones y acciones (externas, laterales y latentes). El estudio realizado ha trabajado seis $T V$ movies y las dos series sitcom estadounidenses más exitosas: las tres entregas de High School Musical (Kenny Ortega, 2006, 2007 y 2008), las dos de Cheetah Girls (Kenny Ortega, 2006 y Paul Hoen, 2008) y la de Camp rock (Matthew Diamond, 2008) y las series Hannah Montana, y Raven.

\section{Estereotipos femeninos y adolescentes}

Los estereotipos comunes de mujeres en la ficción televisiva reproducen los tradicionales del cine, mas algunos casos recientes procedentes en buena medida de videojuegos: la chica buena, el ángel, la virgen, la chica mala, la lolitas, la viuda negra, la madre castradora, la dominátrix ${ }^{1} \ldots$ No obstante, la gran variedad de estereotipos femeninos no se corresponden con las edades de la mujer. Las reinas de las pantallas son las treintañeras. No suelen aplicarse papeles protagonistas a

\footnotetext{
${ }^{1}$ Relación completa en Guarinos (2008).
} 
personajes pertenecientes a dos colectivos de mujeres que comienzan a reclamar su sitio en la representación ficcional televisiva y cinematográfica: las adolescentes y las mayores, es decir las mujeres entre 12 y 18 y desde 45 en adelante. El bloque de estereotipos femeninos correspondiente a la adolescente es un gran paquete que de manera esquemática engloba preadolescentes, adolescentes y primera juventud, de entre 12 y 25 años. Como reflejo de la realidad, ahora las mujeres se reparten en sus apariciones televisivas en series especializadas: series juveniles, series para treintañeros y series familiares.

El boom del fenómeno teenagers reavivado en los últimos años ha proporcionado un elevadísimo número de series que en España se han desarrollado también como producción propia $^{2}$. Este reencuentro con el adolescente como consumidor de productos culturales afecta al cine, a la literatura, a las revistas, a la música popular ${ }^{3}$, y se extiende a los productos de consumo, jugando con que el consumo por imitación es muy alto en este segmento de edad. La necesidad de sentirse en el endogrupo lleva al adolescente a consumir el mismo tipo de series, canciones, libros y otros productos de marca o moda para poder mantener conversaciones y sentirse aceptado, parte de un todo con el que se identifica. De ahí que las empresas, productoras y cadenas de televisión hayan visto en este perfil una audiencia deseada cuyos productos encuentran marcas publicitarias fácilmente para sufragar determinadas franjas horarias de emisión.

Esta estrategia televisiva en España se enmarca en un panorama donde Disney Channel está siendo factor dinamizador. De programas para jóvenes a programas para niños existía un hueco que ha venido a cubrir este canal, cuya imitación están asumiendo las cadenas nacionales públicas y privadas. El problema radica en que al construir estereotipos adolescentes, se están ofreciendo prototipos de imitación. Y el prototipo de esta cadena corresponde a una mentalidad norteamericana globalizada para el mundo entero, una cultura hegemónica que lleva a nuestros adolescentes a afrontar la llegada de mensajes contradictorios, ya que los adolescentes representados en series españolas nada tienen que ver con los estadounidenses. Rincón y Estrella afirman con respecto a televisión e identidad que ésta es "un espejo social, ya que reproduce los modos de vida y las formas de pensar, representar e imaginar que tenemos como sociedad" (2001:47); es un "dispositivo cultural en cuanto ofrece estilos de vida que permiten identificación social. Construye imágenes comunes sobre la existencia, la convivencia y las formas de la imaginación” (2001: 46), instalándose como mediadora del recuerdo, en tanto que muchos de los recuerdos están asociados a los programas que vimos. Y Disney además no se conforma con el envío de relatos, sino que expande su "Disney culture" con otros productos, la mayoría para mujeres y su embellecimiento y para todas las edades. Como las muñecas, se les ofrecen productos especializados que evolucionan con la edad, por ejemplo, en los modelos de belleza propuestos: las muñecas Bratz, cabezonas, zapatonas y agresivas, frente a las Barbies estilizadas y elegantes, ya incluso tatuadas, como productos están más que pensados en cuanto a la

\footnotetext{
${ }^{2}$ Recuérdese el caso de El Internado y Física o química, 18 (Antena 3) o HKM (Hablan, Kantan, Mienten, Cuatro), al hilo de otras series juveniles de gran éxito del tipo $R B D$, procedente de la televisión mexicana.

${ }^{3}$ Los fenómenos literarios Harry Potter (J.K. Rowling, 1999-2007) y Crespúsculo (Stephenie Meyer, 2005-2008) y sus correlativos éxitos cinematográficos son prueba de ello.
} 
especialización por edades que suponen: las Barbies para niñas de entre 3 y 6 años, las Bratzs de 7 a 10, preparándose para no tener muñecas y cambiando el estilo personal, como el de la muñeca, como paso final de la infancia a la adolescencia. En las películas Disney se advierte algo parecido. El gusto del adolescente mantiene como una de sus prioridades aborrecer lo que le gustaba cuando niño. La preadolescencia es la frontera en la que se pasa del gusto por la imagen de animación a la imagen real. La corporeización con la que se encuentra el nuevo espectador, aun estando familiarizado con ella por la televisión, es realista y su concepto de la belleza se hace más complejo. Con la corporeización llega el valor de la belleza y el cine de imagen real encuentra matices en ella que la esquematización de la imagen animada no permite. Esto vuelve también más completo el perfil de representación que aprende y busca el espectador adolescente. Disney lo sabe y sabe que el consumo televisivo aumenta en esas edades, de ahí que el perfil de adolescente tenga que ver con estos dos factores: aumento de complejidad y paso del cine a la tele a través del canal temático Disney Channel.

Es una estrategia muy definida por la ideología, en tanto que el discurso planteado por Disney en su canal parece estar incluso de espaldas a las características de la postelevisión actual (Imbert, 2008) y a favor de una televisión de más fácil lectura y no tan enturbiada por la fragmentación, la hibridación ${ }^{4} \ldots$ para que el mensaje ideológico sea directo ${ }^{5}$. Como parte de esas características televisivas actuales, Imbert habla de la utilización del cuerpo como signo/disfraz hiperfeminizado, en el sentido de que

el cuerpo femenino es objeto, por otra parte, en la postelevisión, de un auténtico trabajo de resemantización, que abarca desde la hiperfeminización, dentro de una afirmación identitaria, protagonizada por las propias mujeres, hasta la reapropiación de los signos de lo femenino, desde lo masculino, en forma de imitación, transformismo. En los dos casos, curiosamente, se trata de una hiperrealización del modelo femenino, dentro de un código barroco, mediante una inflación formal (2008: 156)

todo lo cual termina por ocultar a la mujer tras un disfraz.

\section{Las chicas Disney}

De los relatos ficcionales seleccionados podemos extraer en primer lugar la conclusión de mayor abundancia de personajes femeninos por encima de los masculinos e, incluso en aquellos en que los chicos son mayoría, la chica adolescente espectadora es objetivo destinatario de forma evidente. Así sucede con Camp Rock, interpretada por los Jonas Brothers, tres hermanos que conforman un grupo musical producto Disney, como también lo son las Cheetah Girls. Aunque

\footnotetext{
${ }^{4}$ A excepción de las sitcoms de grupos socio-laborales o la especularidad narcisista de muchos de estos personajes adolescentes.

${ }^{5}$ No es ninguna novedad con respecto al cine. Véase en Croce (2008) la marca ideológica de Disney en sus largos de animación para niños.
} 
sendos productos funcionan con motivaciones diferentes. Los segundos buscan la identificación de las espectadoras con las tres protagonistas; los primeros reclaman a las chicas la observación de los tres hermanos como sujetos del deseo.

El adolescente sufre tres pérdidas: la del cuerpo, la del rol de niño, la de la figura de los padres. El concepto de su mundo se transforma y la imagen que de él le ofrece Disney, también. Mientras a la infancia Disney le ofrece una representación de mujer dulce, elegante, de princesa clásica, donde la belleza interior sustituye a la exterior cuando no la hay, el paso a la preadolescencia, se da hacia ambientes lujosos, ya no regios, y hacia la belleza interior, como bondad, al valor de la belleza ética de la superación de uno mismo y la amistad en limpia competitividad, al menos a simple vista. Se pasa de las brujas a las malas y de los príncipes de sangre azul a los galanes. Al mismo tiempo, indisolublemente se tenderán puentes entre valores y belleza, prolongando los estereotipos de relación entre valor y estética.

De esos tres niveles de pérdidas se pueden extraer tres niveles de análisis: por la pérdida del cuerpo infantil, el nivel físico, iconográfico; por la del rol de niño, el nivel psicológico; y por la de la pérdida de los padres, el nivel relacional o conductual.

\section{Nivel iconográfico}

El uso del cuerpo en las series de ficción televisivas nos habla de la reconstrucción de los universos simbólicos, de un proceso de cambio que ya no se puede decir occidental, sino globalizado, en tanto que afecta a todas las producciones nacionales en mayor o menor medida, dada la influencia en las series del modelo americano extendido. La inseguridad sobre la propia imagen y el anhelo de ser bello constituyen un tema esencial dentro de las series protagonizadas por personajes en edad adolescente, reflejos de una obsesión generalizada. Sobre todo en el caso femenino, ha sido tradicional considerar la juventud como condición necesaria de la hermosura, contagiando a ésta su carácter efímero. La invisibilidad de problemas de salud (alimentarios) relacionados con el físico hace que parezca que no existen dichas enfermedades; nunca son planteadas en las series Disney. Muy al contrario la idea de que el cuerpo no importa y su belleza tampoco entra en la contradicción de que el 99\% de las protagonistas y antagonistas son delgadas. La belleza exterior no es desestimada pero tampoco hipertrofiada. Ahora posee menos valor con respecto a la belleza simbólica interior: el valor de la amistad, de la superación de uno mismo y del esfuerzo para conseguir el éxito. Ese conjunto de elementos constituyen belleza, restando valor a la belleza física, que exagerada pasa a formar parte de la iconografía propia de las villanas, a la inversa dentro del más puro estilo ideológico de Disney. Es el caso de Sharpay, la elegante, rica y coolmalvada de las tres entregas de High School. Lujo, exceso y glamour acercan a este tipo de personajes a los poco edificantes prototipos reales al estilo Paris Hilton. Para el público infantil la identificación entre fealdad y maldad es directa (Amar, Angarita y Cabrera, 2003) ${ }^{6}$. La belleza, uno de los factores más

\footnotetext{
${ }^{6}$ Los niños suelen asociar la belleza con el color, el alimento y la bondad; y lo feo con lo sucio, viejo y nocivo; la bondad con afecto, la cercanía física y lo malo con lo no afecto y con no dar. Asocian el dinero con comprar y
} 
perceptibles a través de la mirada, es el valor que más sufre en la formación de mentalidades. La tesis doctoral de Ruiz Pacheco (1999) evaluaba el atractivo físico sobre modelos audiovisuales en niños y adolescentes llegando a conclusiones muy interesantes.

Los estereotipos que muestran los niños de 5 y 8 años pueden resumirse en lo bello es bueno, asociando características positivas a los modelos más atractivos. La evolución con la edad refleja la mayor complejidad del pensamiento de los jóvenes y adolescentes, pero se produce un efecto de "inversión" en algunas de las características atribuidas. Los modelos de poco atractivo se asocian más a actividades interesantes y los modelos atractivos se asocian en mayor medida a actividades vitales, pero más triviales o superficiales. (1999: 232)

No obstante, el efecto "halo" lleva a que desde las valoraciones que se hacen de los personajes a las valoraciones que se hacen de las actividades que estos proponen. Es decir, cuando los personajes son atractivos las actividades que hacen son atractivas y no hay actividades atractivas si los personajes no lo son. Además en los adolescentes, cuando se les pide describir personajes a los que les gustaría parecerse lo hacen con atributos psicológicos y de autoconcepto y no físicos o externos. Precisamente esta malvada referida es la que más se esfuerza por parecer una princesa Disney: rubia, delgada, cargada de complementos, abusando del color rosa y brillando rutilantemente gracias a lentejuelas y brillantes, pero a esta edad esta apariencia ya resulta ridícula y no deseable. Las buenas son más sencillas, modernas, urbanitas, cómodas y con intenciones de apariencias físicas agradables sólo para ocasiones especiales (bailes de fin de curso), eso sí, desposeídas de rasgos que las identifiquen con tribus urbanas que puedan descomponer el clima Disney (piercings, tatuajes, maquillajes...) y su ideología conservadora. La novedad que presentan estos cuerpos es la pertenencia a diversas razas, no tanto como ejemplo de integración sino como cumplimiento de exigencias de audiencias, puesto que estas series y telefilms están pensados para emisión mundial donde algún personaje negro, oriental o sudamericano pueda servir de elemento identitario en su emisión de diversos países. Todo ello está muy relacionado con los recientes estudios sobre el cuerpo y la tendencia de teorías sobre el embodiment, especialmente desarrollada en filosofía y psicología como embodied cognition y embodied imagination. (Rohrer, 2005 y 2006). En estas teorías se afirma que cada cultura tiene una relación especial con su cuerpo y su modo de situarlo en el contexto. En los productos Disney Channel el cuerpo racial está vacío de contenido, subsumido por el sistema y no conlleva sus propias características, no es más que un cuerpo diferente y minoritario.

trabajar; la autoridad la ven en padres, profesores y personajes del barrio (tendero, por ejemplo) y otros familiares. La madre es autoridad porque lava y da de comer, el padre porque trae dinero. La escuela es el sitio para jugar y estudiar. Datan la felicidad con tener comida, regalos y afecto. La amistad la relacionan con el colegio y la familia y, luego, con los vecinos. Relacionan estar sano con poder jugar, comer y estar alegre. Y la muerte la vinculan con la no movilidad, la vejez y la violencia. Asocian la masculinidad con la ausencia, el trabajo, el consumo de alcohol y mujeres, con la fuerza y el juego; la feminidad con la comida, el trabajo dentro y fuera del hogar, con la bondad, la sumisión y la compañía del hombre. Concepción patriarcal tradicional. 


\section{Nivel psicológico}

Desde esta perspectiva la chica Disney es una "adulescente". Es un personaje que practica una competitividad que se acompaña con un alto sentido de la culpa y el arrepentimiento. Son triunfadoras. Los personajes negativos quieren éxito sin esfuerzo salvo el que se derive de las artimañas pero son castigadas con no alcanzarlo nunca, pues triunfa la justicia y el mérito personal basado en el trabajo duro y la superación de uno mismo. Se ven envueltas en tramas de comedia o melodrama romántico al más puro esquema narrativo de triángulo amoroso donde dos chicas luchan por un chico, al estilo clásico patriarcal. Algunas de ellas, estrellas de televisión, reciben en sus series los nombres reales de las actrices: Raven o Miley Cyrus, quien hace en la serie de una chica triunfadora en el mundo de la música llamada Miley cuyo nombre artístico es Hannah Montana, en clara confusión entre realidad y ficción. Todas demuestran unas psicologías adultas de gran madurez con momentos de ingenuidad, fruto de la poca experiencia. Son muy independientes y arriesgadas. Y aunque no se arredran ante nada, sí sucumben ante el amor. No existen muchas diferencias entre las mujeres adultas representadas en series americanas (Menéndez, 2008), quienes son independientes, profesionales, hermosas y enamoradas. En este sentido presentan una psicología avanzada, tal como afirma Lotz (2006); las series de televisión están redefiniendo los roles de mujer, añadiendo algunos aspectos positivos femeninos con objeto de rescatar audiencias femeninas, pasando del único rol doméstico y entrando en roles de no dependencia de un varón. Aunque persiste el problema de encontrar pareja, dando a entender que si no la encuentra parece que está incompleta, llegando a rivalizar con otras mujeres por el mismo hombre, como se repite también en High School, en Camp Rock y en series como Hannah Montana o Raven.

\section{Nivel conductual}

La actitud de esta chica adolescente es puritana como rasgo básico. Y es un comportamiento que comparte con los chicos. Estas mujeres, a pesar de su independencia y distanciamiento de la familia (aunque no falta de respecto hacia progenitores), se encuentran subyugadas al grupo, por el que sufren dependencia, un grupo que suele ser mixto, pero puede serlo sólo de chicas. El sentido de liderazgo se produce en las chicas protagonistas escasamente, forman pandillas más igualitarias, inter pares. Es un personaje desconocedor del $\mathrm{sexo}^{7}$, la homosexualidad, la delincuencia, el alcohol o las drogas, que son siempre temas tabú en estas series o $t v$ movies. La presencia de la familia es casi inexistente como entorno productor de temas, tramas o conflictos porque estas chicas permanecen dentro de un microcosmos urbanita reducido al instituto o al lugar donde se reúnen los amigos. En las sitcoms, el hogar es el lugar de reunión y convivencia

\footnotetext{
7 Los hermanos Jonas han puesto de moda el "anillo de pureza", adorno que distingue a quien lo lleva como practicante de la castidad, posición moral que rechaza el sexo prematrimonial.
} 
familiar pero las relaciones representadas suelen mantener relación esporádica con padres y hermanos. La diferencia con series españolas es tangible. El prototipo español es una joven con ideas muy claras, independiente, de aspecto natural y sin obsesiones por el físico, que afrontan sus problemas con valor y lógica y actuando con independencia sin tener como referentes a sus padres. La amistad es altamente valorada, dentro de una amplia tolerancia que contempla el perdón entre ellos y la vuelta a la integración en el grupo, incluso siendo "la mala", pues el establecimiento maniqueo de buenas y malas se mantiene muy claramente en la ficción americana. Se trata de un mundo representado que por oposición, por ejemplo con Física o química (Antena 3), parece anclarse en un mundo irreal donde nunca se representaría las relaciones desiguales entre un alumno y su profesora, o las fiestas petting, fiestas de adolescentes para beber, drogarse y mantener sexo libre sin penetración. En nuestras series el sexo se hace explícito, aparecen personajes homosexuales ${ }^{8}$, alumnas (El internado) que mantienen relaciones con su padrastro, o profesoras con alumnos (también El Internado). Nuestros adolescentes son poco ambiciosos, carecen de grandes aspiraciones profesionales. La belleza, el éxito y la superación personal no son problemas para ellas ${ }^{9}$. Por el otro lado, las series americanas hablan de todo lo contrario: no existe en ellas nada de lo que en las series españolas es vida cotidiana. En ese sentido el adolescente español cuenta con un referente ficcional que lo aboca a la búsqueda del éxito al estilo Hannah Montana ${ }^{10}$, personajes que demuestran que es fácil ser famoso con un comportamiento humilde y trabajador, en oposición con lo ofrecido por nuestras producciones, impensable para una serie americana ${ }^{11}$.

\section{Caducado mundo Disney}

Como tan sugerentemente titula la introducción de su libro Amelia Valcárcel (2008), Feminismo en el mundo global: época de cambios o cambio de época, la ley del agrado y la tiranía de la belleza continúan existiendo aunque el envoltorio varíe, llegando a la conclusión de que la igualdad es en algunos entornos un espejismo. Y Disney es uno de ellos en lo que a mujeres adolescentes se refiere. "La conquista de espacios y derechos no ha frenado una carrera hacia la perfección que en bastantes ocasiones es enfermiza” (2008: 248). Esta perfección en la propuesta Disney debe mantener el equilibrio de la perfección de actitud relacional, la psicológica de madurez y la física de belleza porque las chicas buenas, trabajadoras y sencillas si no son ambiciosas, amorosas y

\footnotetext{
${ }^{8}$ El primer personaje homosexual es de Al salir de clase (Tele 5, 1997-2002).

${ }^{9}$ No consideramos aquí la serie Sin tetas no hay paraíso (Antena 3), por considerarla para adultos aunque fuera de gran predicamento entre los adolescentes. En esta serie la búsqueda del éxito y la salida de un barrio pobre pone a las chicas ante la tesitura de aceptar caer en las drogas, la delincuencia y la prostitución por supervivencia.

${ }^{10}$ Genera mil millones de dólares en música, imagen y productos que se venden con su nombre y ha sido la adolescente real más adinerada del mundo.

${ }^{11}$ El panorama americano no Disney ha protagonizado recientemente el escándalo del estreno de al serie Gossip Girl (CBS, 2007) que se ha promocionado con el eslogan "No dejen que sus hijos la vean", perfecto para que los adolescente deseen verla. Es un drama adolescente basado en las novelas de Cecily von Ziegeser, centrado en un colegio de alto nivel en Nueva York, niños ricos que juegan peligrosamente con sexo y drogas, con la moda como telón de fondo.
} 
hermosas no llegan a ser Hannah Montana o Sharpay Evans, aunque parezca que sí. Son unas mujeres obligadas a parecer maduras. Se cumple así lo que dicen Perales y Pérez: "Cada vez más el mundo del menor se construye simbólicamente como un periodo de espera preadolescente en el que penetran más los elementos de estilo de vida del actual modelo hegemónico de identidad: la juventud” (2008: 302). No es ésta la deconstrucción del cuento de hadas que se ha venido haciendo desde el Feminismo. El imperio corporativo Disney ha sido puesto en evidencia desde muchos aspectos. Uno de ellos demuestra, como en el título del trabajo de Patricia Digón (2006), lo caduco de la propuesta Disney Channel a pesar de su éxito entre las chicas:

La imagen de inocencia y defensa de la moral que nos vende Disney dificulta un análisis crítico de productos como las películas Disney de dibujos animados. Sin embargo, analizando de forma crítica el contenido de esas historias podemos encontrar numerosos estereotipos que refuerzan valores sexistas, racistas y clasistas. (165-166)

Esta situación varía para la mujer adolescente, sólo cambia la apariencia para cumplir con lo políticamente correcto y esquivar las críticas por evidencia de sexismo. Úrsula en La sirenita le decía a Ariel:

Tienes tu belleza, tu linda cara. Y no debes subestimar la importancia que tiene el lenguaje corporal. Hablando mucho enfadas a los hombres. Se aburren y no dejas buen sabor, pues les causan más placer las chicas que tienen pudor. ¿No crees que estar callada es lo mejor?

Ahora si fuera adolescente diría lo mismo pero referido a la ambición y la consecución del éxito con esfuerzo y tenacidad, manteniéndose asexuada y casta pero justa, organizando un universo simbólico metafórico, fantasioso e irreal. Y eso sí, muy correcto, para cubrir el expediente en lo que se refiere a raza, clase y género.

\section{Referencias}

Croce, M. (2008) El cine infantil en Hollywood. Una pedagogía fílmica del sistema político metropolitano. Málaga: Alfama.

Digón, P. (2006) "El caduco mundo de Disney: propuesta de análisis crítico en la escuela". Comunicarn. 26.pp.163-169.

Guarinos, V. (2008) “Mujer y cine”. En: Loscertales, F.; Núnez, T. (eds.) Los medios de comunicación con mirada de género. Sevilla: Instituto de la Mujer.pp.103-120.

Imbert, G. (2008) El transformismo televisivo. Madrid: Cátedra.

Lotz, A. (2006) Series de televisión redefinen los roles de mujer. Edición online obtenida el 20 de marzo de 2009 en http://www.umich.edu/Es/news/06/pr0443.php.

Menéndez, M.I. (2008) Discursos de ficción y construcción de la identidad de género en televisión. Palma de Mallorca: Universidad de las Islas Baleares. 
Perales, A.; Pérez Chica, Á. (2008) “Aprender la identidad: zqué menores ven los menores en tv?”. Comunicarn. 31.pp. 299-304.

Rincón, O.; Estrella, M. (2001) Televisión: pantalla e identidad. Ciudad de México: El Conejo.

Rohrer, T. (2006) “The Body in Space. Dimensions of embodiment". En: Zlatec, J. et al (ed.) Body, Language and Mind. Berlin: Mouton de Gruyter.

Rohrer, T. (2005) "Image Schemata in the Brain”. En: Hampe, B.; Grady, J. (eds.) From Perception to Meaning: Image Schemas in Cognitive Linguistics. Berlin: Mouton de Gruyter.pp. 165-196.

Valcárcel, A. (2008) Feminismo en el mundo global: época de cambios o cambio de época. Madrid: Cátedra. 